Article

\title{
Heterogeneous Fenton-Like Degradation of $p$-Nitrophenol over Tailored Carbon-Based Materials
}

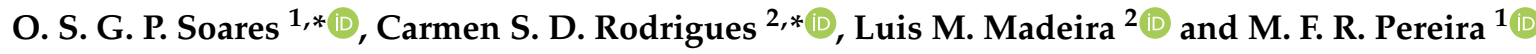 \\ 1 LSRE-LCM - Laboratory of Separation and Reaction Engineering-Laboratory of Catalysis and Materials, \\ Faculty of Engineering, University of Porto, Rua Dr. Roberto Frias, 4200-465 Porto, Portugal; \\ fpereira@fe.up.pt \\ 2 LEPABE - Laboratory for Process Engineering, Environment, Biotechnology and Energy, Faculty of \\ Engineering, University of Porto, Rua Dr. Roberto Frias, 4200-465 Porto, Portugal; mmadeira@fe.up.pt \\ * Correspondence: salome.soares@fe.up.pt (O.S.G.P.S.); csdr@fe.up.pt (C.S.D.R.); \\ Tel.: +351-220-414-874 (O.S.G.P.S.); +351-220-414-851 (C.S.D.R.)
}

Received: 28 January 2019; Accepted: 9 March 2019; Published: 14 March 2019

\begin{abstract}
Activated carbon (AC), carbon xerogel (XG), and carbon nanotubes (CNT), with and without $\mathrm{N}$-functionalities, were prepared. Catalysts were obtained after impregnation of these materials with $2 \mathrm{wt} . \%$ of iron. The materials were characterized in terms of $\mathrm{N}_{2}$ adsorption at $-196{ }^{\circ} \mathrm{C}$, elemental analysis (EA), and the $\mathrm{pH}$ at the point of zero charge $\left(\mathrm{pH}_{\mathrm{PZC}}\right)$. The $p$-nitrophenol (PNP) degradation and mineralization (assessed in terms of total organic carbon-TOC-removal) were evaluated during adsorption, catalytic wet peroxidation (CWPO), and Fenton process. The textural and chemical properties of the carbon-based materials play an important role in such processes, as it was found that the support with the highest surface area -AC- presents the best performance in adsorption, whereas the materials with the highest mesopore surface area -XG or Fe/XG- lead to best removals by oxidation processes (for XG it was achieved 39.7 and $35.0 \%$ and for $\mathrm{Fe} / \mathrm{XG} 45.4$ and $41.7 \%$ for PNP and TOC, respectively). The presence of N-functionalities increases such removals. The materials were reused in consecutive cycles: the carbon-based materials were deactivated by hydrogen peroxide, while the catalysts showed high stability and no Fe leaching. For the support with superior performances -XG-, the effect of nitrogen content was also evaluated. The removals increase with the increase of the nitrogen content, the maximum removals $(81 \%$ and $65 \%$ for PNP and TOC, respectively) being reached when iron supported on a carbon xerogel doped with melamine was used as catalyst.
\end{abstract}

Keywords: carbon xerogel; carbon nanotubes; activated carbon; adsorption; catalytic wet peroxidation; heterogeneous Fenton's oxidation; $p$-nitrophenol

\section{Introduction}

Nowadays, the research and development of efficient wastewater treatment technologies have received huge attention from the scientific community, especially the treatment methods called advanced oxidation processes (AOPs) [1,2]. Among the innumerous AOPs, the Fenton reaction stands out, which has been widely studied in the treatment of effluents because it is recognized as a "green technology" (i.e., this process uses environmentally friendly reagents), implies low capital cost, is able to operate at atmospheric pressure and room temperature with a simple technology, is non selective (i.e., degrade various pollutants), improves the biodegradability and reduces the toxicity of the effluents, and is an efficient process [3-5].

The high efficiency of Fenton reaction in degradation of organic matter is due to the utilization of hydroxyl radicals, which are the second species with highest oxidation potential $(2.8 \mathrm{eV})$ [6]. These 
radicals result from the catalytic decomposition of hydrogen peroxide, at low $\mathrm{pH}$ values, in the presence of iron (II) species (Equation (1)) [7]:

$$
\mathrm{Fe}^{2+}+\mathrm{H}_{2} \mathrm{O}_{2} \rightarrow \mathrm{Fe}^{3+}+\mathrm{HO}^{\bullet}+\mathrm{OH}^{-}
$$

However, other reactions also occur at same time, for instance: (i) iron (III) reacts with hydrogen peroxide (Equation (2)) or $\mathrm{HO}_{2}{ }^{\bullet}$ (Equation (3)) and forms iron (II) again—catalyst regeneration, and (ii) undesirable hydroxyl radicals scavenging by excess of hydrogen peroxide (Equation (4)) and/or iron (II) (Equation (5)) [7]:

$$
\begin{gathered}
\mathrm{Fe}^{3+}+\mathrm{H}_{2} \mathrm{O}_{2} \rightarrow \mathrm{Fe}^{2+}+\mathrm{HO}_{2}^{\bullet}+\mathrm{H}^{+} \\
\mathrm{Fe}^{3+}+\mathrm{HO}_{2}^{\bullet} \rightarrow \mathrm{Fe}^{2+}+\mathrm{O}_{2}+\mathrm{H}^{+} \\
\mathrm{HO}+\mathrm{H}_{2} \mathrm{O}_{2} \rightarrow \mathrm{H}_{2} \mathrm{O}+\mathrm{HO}_{2}^{\bullet} \\
\mathrm{HO}^{\bullet}+\mathrm{Fe}^{2+} \rightarrow \mathrm{Fe}^{3+}+\mathrm{HO}^{-}
\end{gathered}
$$

The principal disadvantage of the homogeneous Fenton process is the introduction of iron into the treated water, so an additional separation step is required to remove/recover it. An alternative strategy, in order to overcome this drawback, is the immobilization of the catalyst on a porous solid matrix. Distinct materials, like zeolites, pillared clays, silica, silicalites, and carbons have been used to support iron [8-14].

Carbon materials are widely used as supports because they are very flexible materials, since their textural and chemical properties can be easily tailored by physical or chemical treatments $[15,16]$. Among the carbon materials, activated carbon (AC) is the most reported in the literature as iron support to be used as a catalyst for the Fenton reaction [13,14,17-20]. Recently, carbon nanotubes (CNT) [21-23] and carbon xerogels (XG) [24] have received intensive attention as iron supports due to their interesting properties when compared with other carbon-based materials, such as mechanical resistance, low limitations to mass transfer, high thermal stability in oxidation conditions, high electronic properties for CNT [25], high purity, mesoporous structure with good pore distribution, and high surface area for $X G[26]$.

The presence of nitrogen groups on the surface of carbon-based materials improves their catalytic performance for advanced oxidation processes. This is explained by the increase of the electronic density, and consequently the surface basicity, which favors the interaction between the organic compounds and the support [17].

$p$-Nitrophenol (PNP) was used in this work as a model compound because it is commonly present in several industrial wastewaters such as those resulting from manufacturing of drugs, dyes, fungicides, and explosives [27]. PNP is toxic, carcinogenic, and mutagenic, needing to be removed from effluents before their discharge into water bodies. Due to its toxic nature to microorganisms, biological degradation is not suitable or presents slow degradation rates [28,29]; so, the use of AOPs, particularly of heterogeneous Fenton-like process, is of vital importance. There are some studies where this process is applied to degrade PNP using as catalysts acid-activated fly ash [30], activated carbon impregnated with iron and doped with nitrogen [17], $\mathrm{CuO} /$ zeolite [31], transition metals (such as $\mathrm{Ti}, \mathrm{Cr}$, $\mathrm{Mn}, \mathrm{Co}$ and Ni) on magnetite [32], magnetite/silica microspheres [33], and magnetic $\mathrm{Fe}^{0} / \mathrm{Fe}_{3} \mathrm{O}_{4} /$ coke composite [34].

The main aim of this work is to evaluate the effect of the carbon-based materials nature (AC, CNT, and XG) with different textural properties and nitrogen functionalities in adsorption, catalytic wet peroxidation (CWPO) and heterogeneous Fenton oxidation of PNP. To the best of our knowledge, there are no studies combining the evaluation of all these parameters under the same experimental conditions. 


\section{Results and Discussion}

\subsection{Carbon-Based Materials Characterization}

The results shown in Table 1 clearly show that the activated carbon sample presents the largest BET surface area - $S_{B E T}-\left(824 \mathrm{~m}^{2} \mathrm{~g}^{-1}\right)$, while the carbon nanotubes are the carbon-based materials with the lowest surface area $\left(273 \mathrm{~m}^{2} \mathrm{~g}^{-1}\right)$. In addition, activated carbons are mainly microporous materials, whereas carbon nanotubes have a mesoporous nature and carbon xerogels present intermediate textural properties with a BET surface area of $572 \mathrm{~m}^{2} \mathrm{~g}^{-1}$ and a mesoporous area $\left(S_{\text {meso }}\right)$ of $290 \mathrm{~m}^{2} \mathrm{~g}^{-1}$. The N-doping with melamine or urea induces a reduction of the surface area, suggesting that the $\mathrm{N}$-groups introduced may block the access of $\mathrm{N}_{2}$ molecules to the pores. There is only a slight decrease of the surface area of the iron catalysts (Fe/y, where $y$ is the carbon material used as support) compared to the unloaded carbon-based materials, confirming that the textural properties of the supported catalysts are not significantly different from the corresponding supports. Also, in this case, access to the pores may be partially blocked by iron species.

Table 1. Textural properties of the carbon-based materials *.

\begin{tabular}{|c|c|c|c|c|}
\hline Sample & $\begin{array}{c}S_{B E T} * * \\
\left( \pm 10 \mathrm{~m}^{2} \mathrm{~g}^{-1}\right)\end{array}$ & $\begin{array}{c}S_{\text {meso }}{ }^{* *} \\
\left( \pm 10 \mathrm{~m}^{2} \mathrm{~g}^{-1}\right)\end{array}$ & $\begin{array}{c}V_{\text {micro }}{ }^{* *} \\
\left( \pm 0.01 \mathrm{~cm}^{3} \mathrm{~g}^{-1}\right)\end{array}$ & $\begin{array}{c}V_{p P / P o=0.95} * * \\
\left(\mathrm{~cm}^{3} \mathrm{~g}^{-1}\right)\end{array}$ \\
\hline $\mathrm{AC}$ & 824 & 196 & 0.286 & 0.492 \\
\hline ACM & 730 & 174 & 0.229 & 0.408 \\
\hline CNT & 273 & 273 & 0 & 0.573 \\
\hline CNTM & 222 & 222 & 0 & 0.512 \\
\hline XG & 572 & 290 & 0.150 & 0.497 \\
\hline XGM & 510 & 117 & 0.182 & 0.398 \\
\hline XGU & 513 & 174 & 0.158 & 0.486 \\
\hline $\mathrm{Fe} / \mathrm{AC}$ & 807 & 179 & 0.288 & 0.479 \\
\hline $\mathrm{Fe} / \mathrm{ACM}$ & 717 & 171 & 0.251 & 0.408 \\
\hline $\mathrm{Fe} / \mathrm{CNT}$ & 266 & 266 & 0 & 0.540 \\
\hline $\mathrm{Fe} / \mathrm{CNTM}$ & 205 & 205 & 0 & 0.471 \\
\hline $\mathrm{Fe} / \mathrm{XG}$ & 564 & 273 & 0.149 & 0.491 \\
\hline $\mathrm{Fe} / \mathrm{XGM}$ & 490 & 133 & 0.168 & 0.402 \\
\hline $\mathrm{Fe} / \mathrm{XGU}$ & 486 & 166 & 0.147 & 0.449 \\
\hline
\end{tabular}

* AC—activated carbon; CNT—carbon nanotubes; XG—xerogel; M-stands for melamine-doped materials; $\mathrm{U}$-stands for urea-doped materials; $\mathrm{Fe}$-stands for iron-containing catalysts. $* * S_{B E T}$-surface area; $S_{\text {meso }}$-mesopore surface area; $V_{\text {micro }}$-micropore volume, $V_{p}$ - total specific pore volume.

The doping with melamine as $\mathrm{N}$-precursor results in the incorporation of a large amount of nitrogen (between 3.4\% and 5.3\%) on the surface of the carbon-based materials, as determined by elemental analysis ( $\mathrm{N}_{\mathrm{EA}}$-Table 2). In the case of the carbon xerogels, for which two types of nitrogen precursors were used, it was observed that the doping with melamine allows the incorporation of more nitrogen $(4.51 \%)$ than urea $(3.30 \%)$, since the molecule of melamine has more nitrogen atoms (six) than urea (two). The N1s spectrum, obtained by X-ray photoelectron spectroscopy (XPS), revealed the presence of quaternary nitrogen $(\mathrm{N}-\mathrm{Q})$, pyrrole $(\mathrm{N}-5)$, and pyridinic $(\mathrm{N}-6)$ structures on samples ACM and CNTM, whereas samples XGU and XGM only present N-5 and N-6 groups. The N-6 group (B.E. $=399.0 \pm 0.2 \mathrm{eV}$ ) is the most abundant species in all samples, followed by the N-5 group (B.E. $=400.4 \pm 0.3 \mathrm{eV}$ ). The corresponding binding energies and percentages of the $\mathrm{N}$-functionalities are presented in Table 2. All the carbon-based materials present a neutral/basic character, with the $\mathrm{pH}$ at the point of zero charge $\left(\mathrm{pH}_{\mathrm{pzc}}\right)$ values between 7.0 and 8.8 . 
Table 2. Chemical properties of the carbon-based materials *.

\begin{tabular}{cccccccccc}
\hline Sample & \multicolumn{2}{c}{$\mathbf{N}$ Content } & \multicolumn{2}{c}{$\mathbf{N - 6}^{* *}$} & \multicolumn{2}{c}{$\mathbf{N - 5}{ }^{* *}$} & \multicolumn{2}{c}{$\mathbf{N}-\mathbf{Q}^{* *}$} & $\mathbf{p H}_{\mathbf{P Z C}}( \pm \mathbf{0 . 1})$ \\
\hline & $\begin{array}{c}\mathbf{N}_{\text {EA }} \\
\mathbf{( w t . \% )}\end{array}$ & $\begin{array}{c}\mathbf{N}_{\mathbf{X P S}} \\
\mathbf{( w t . \% )}\end{array}$ & $\begin{array}{c}\text { B.E. } \\
\mathbf{( e V )}\end{array}$ & $\mathbf{( w t . \% )}$ & $\begin{array}{c}\text { B.E. } \\
\mathbf{( e V )}\end{array}$ & $\mathbf{( w t . \% )}$ & $\begin{array}{c}\text { B.E. } \\
\mathbf{( e V )}\end{array}$ & $\mathbf{( w t . \% )}$ & \\
\hline AC & 0.15 & - & - & - & - & - & - & - & 7.5 \\
ACM & 3.40 & 3.14 & 398.4 & 1.68 & 400.0 & 1.07 & 401.4 & 0.39 & 7.5 \\
CNT & 0.01 & - & - & - & - & - & - & - & 7.0 \\
CNTM & 5.31 & 4.8 & 398.9 & 2.24 & 400.3 & 1.66 & 401.5 & 0.87 & 7.5 \\
XG & 0 & - & - & - & - & - & - & - & 8.0 \\
XGM & 4.51 & 4.64 & 398.5 & 2.48 & 400.6 & 2.16 & - & - & 8.8 \\
XGU & 3.30 & 3.87 & 398.6 & 2.18 & 400.7 & 1.70 & - & - & 8.3 \\
\hline
\end{tabular}

* AC-activated carbon; CNT-carbon nanotubes; XG-xerogel; M-stands for melamine-doped materials; $\mathrm{U}-$ stands for urea-doped materials. ${ }^{* *} \mathrm{~N}-6$ - pyridinic nitrogen structure; N-5-pyrrole nitrogen structure; $\mathrm{N}-\mathrm{Q}-$ quaternary nitrogen structure.

\subsection{Adsorption in Carbon-Based Materials}

First, the adsorption of PNP in the supports (AC, CNT, and XG) and supports doped with melamine (ACM, CNTM, and XGM) was assessed. In Figure 1a,b it is possible to observe that PNP and TOC removals increase in the following order: $\mathrm{CNT}<\mathrm{XG}<\mathrm{AC}$ materials. Ribeiro et al. [35] observed the same tendency for adsorption of 2-nitrophenol. The amount of PNP adsorbed increases when $\mathrm{N}$-doped materials are used, maintaining the same trend. For all samples PNP and TOC removals are nearly the same, evidencing that only adsorption phenomenon is occurring.

a

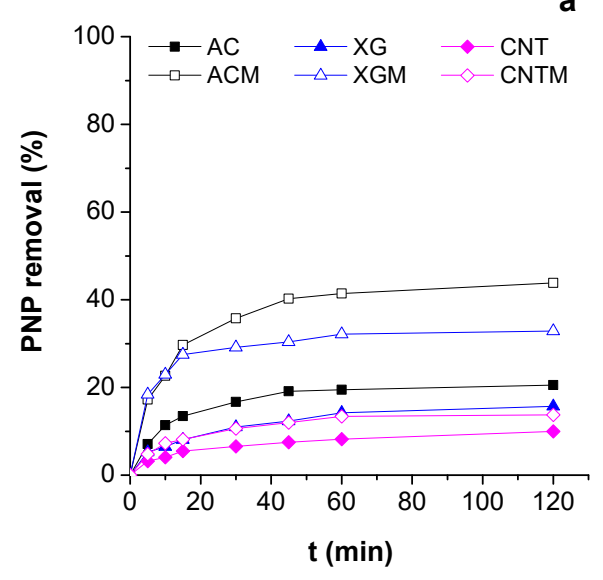

C

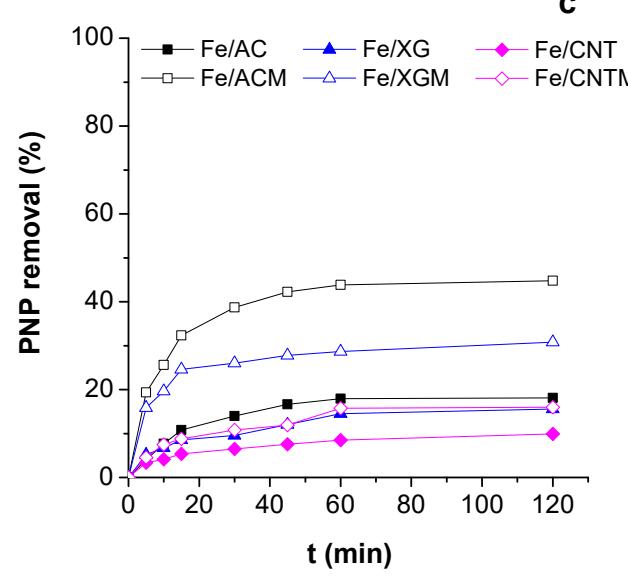

b
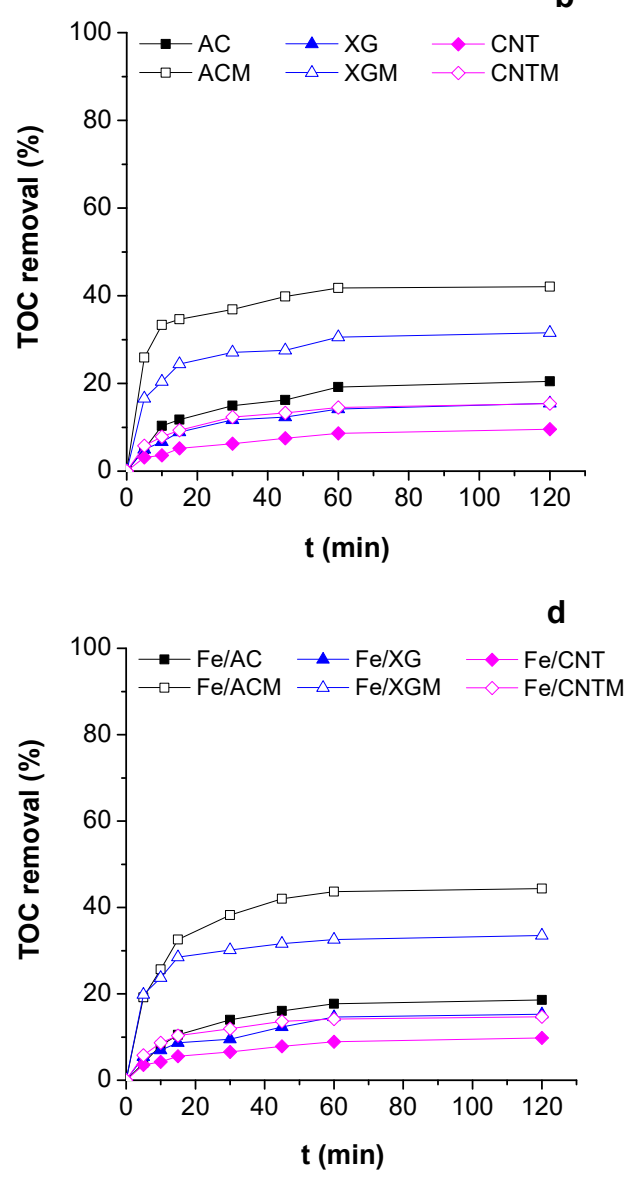

Figure 1. $p$-nitrophenol (PNP) and total organic (TOC) removal during adsorption with the carbon supports $(\mathbf{a}, \mathbf{b})$ and with the iron-containing catalysts $(\mathbf{c}, \mathbf{d})\left(\mathrm{pH}=3.0, \mathrm{~T}=30^{\circ} \mathrm{C}\right.$, [support] $=0.25 \mathrm{~g} \mathrm{~L}^{-1}$ and $\left.[\mathrm{PNP}]=3.6 \mathrm{mmol} \mathrm{L}^{-1}\right)$. 
The adsorption capacity of the materials is related to their specific surface area (if surface chemistry properties of the carbon materials are similar), as evidenced by the fact that the lower amount of PNP adsorbed was obtained when CNT was used, which presents the lowest BET surface area $\left(273 \mathrm{~m}^{2} \mathrm{~g}^{-1}\right.$ - see Table 1), while the highest amount was obtained with the AC support that presents the highest surface area $\left(824 \mathrm{~m}^{2} \mathrm{~g}^{-1}\right.$ —see Table 1); the same tendency was reported by Messele et al. [36], who found that the highest adsorption capacity towards phenol was obtained with the carbon xerogel with the largest surface area. The adsorption results confirm that the textural properties of the supports play an important role in adsorption of PNP, this being demonstrated by the strong linear correlation found between PNP removal after $2 \mathrm{~h}$ and the materials BET surface areas (determination coefficient $\left(r^{2}\right)>0.999$; Figure S1a-see Supporting Information section). However, other factors also play an important role, namely the surface chemistry.

The presence of $\mathrm{N}$-containing groups on the surface of the supports led to an increase in their adsorption capacity, since the removal of PNP and TOC increased-see Figure 1a,b. This improvement is related to the $\mathrm{N}$-functionalities incorporated on the surface of the materials, which allow to increase the surface basicity of the supports, i.e., increase the $\pi$ electronic density of the carbons layers [37], favoring the interaction between the aromatic compound and supports. Similar results were observed by other authors $[17,20,36-39]$. In view of these results, it can be concluded that the surface chemistry properties also play a relevant role in the adsorption process (see Figure $\mathrm{S} 1 \mathrm{~b} ; r^{2}>0.99$ ).

The same tendency was observed for adsorption runs with supports impregnated with iron. The PNP and TOC removals shown in Figure 1c,d, reached with iron-containing catalysts, were similar to those obtained with the supports. This result is in accordance with the expected trend, since the catalysts and corresponding supports present similar BET surface areas (see Table 1) and surface chemistries.

\subsection{Catalytic Wet Peroxidation (CWPO) Using the Supports as Catalysts}

In order to evaluate the catalytic performance of the carbon-based materials (without iron) in peroxidation and mineralization of PNP, experiments were carried out in the presence of each support and oxidizing agent (hydrogen peroxide). The PNP and TOC removals are shown in Figure 2.

The PNP and TOC removals were very low ( $11.0 \%$ and $8.5 \%$, respectively, after $2 \mathrm{~h}$-Figure $2 \mathrm{a}, \mathrm{b})$ in the presence of the oxidant alone due to the fact that $\mathrm{H}_{2} \mathrm{O}_{2}$ has a low oxidation potential $(1.8 \mathrm{eV})$. As shown in Figure 2, the presence of AC, CNT, or XG supports increases the efficiency of the process comparatively to either adsorption (Figure 1) or experiments where only oxidant has been used (Figure 2), which is due to the formation of hydroxyl radicals (see Figure 3a) by the decomposition of hydrogen peroxide on the surface of the carbon-based materials. This is in line with a previous work [17] and in accordance with the radical mechanism of catalytic decomposition of $\mathrm{H}_{2} \mathrm{O}_{2}$ using activated carbon (Equation (6)) proposed by Santos et al. [40]. The PNP and TOC removals increase in the following order: XG > AC > CNT. Nevertheless, it should be taken into account that in these experiments, part of the PNP (and organic compounds formed) are adsorbed on the carbon-based materials, so that there is the contribution of both reaction and adsorption; therefore, the PNP and TOC removals obtained by reaction only were estimated discounting from those data the removals reached by adsorption (i.e., without oxidant). Such data are shown in Figure 2c, being noticed that the removals reached by reaction are higher for the XG, followed by the CNT and finally the AC. XG and CNT present better catalytic performances probably due to their mesoporous nature; in fact, they present higher mesoporous areas (290 and $273 \mathrm{~m}^{2} \mathrm{~g}^{-1}$ for XG and CNT, respectively-see Table 1) than AC. In addition, Figure $3 \mathrm{a}$ also reveals that the mesoporosity of the materials benefits the decomposition of $\mathrm{H}_{2} \mathrm{O}_{2}$ into hydroxyl radicals. Actually, in addition to the fastest consumption of hydrogen peroxide, kinetics of hydroxyl radicals formation (assessed through the blank experiments) is also fastest for the mesoporous materials XG or CNT; this behavior can be related to the decrease of internal diffusional limitations with the increase of mesoporosity. 


$$
\mathrm{ACM}+\mathrm{H}_{2} \mathrm{O}_{2} \rightarrow \mathrm{ACM}^{+}+\mathrm{OH}^{-}+\mathrm{HO}^{\bullet}
$$

Again, the N-functionalities on the surface of the carbon-based materials benefit the CWPO (see Figure $2 \mathrm{a}, \mathrm{b}$ ) increasing the hydrogen peroxide consumption and hydroxyl radicals formation in blank runs (see Figure 3a,c), following the same tendency of undoped supports. Sun et al. [41] obtained a greater phenol removal by sulfate radicals when using $\mathrm{N}$-doped carbon nanotubes as catalysts. Rodrigues et al. [17] and Messele et al. [38] also observed the positive effect of the presence of N-groups on the surface of activated carbon in PNP and phenol removal, respectively, by wet peroxidation. Finally, Santos et al. [42] found higher wet oxidation efficiency of phenol when using carbon nanotubes doped with melamine as catalyst.
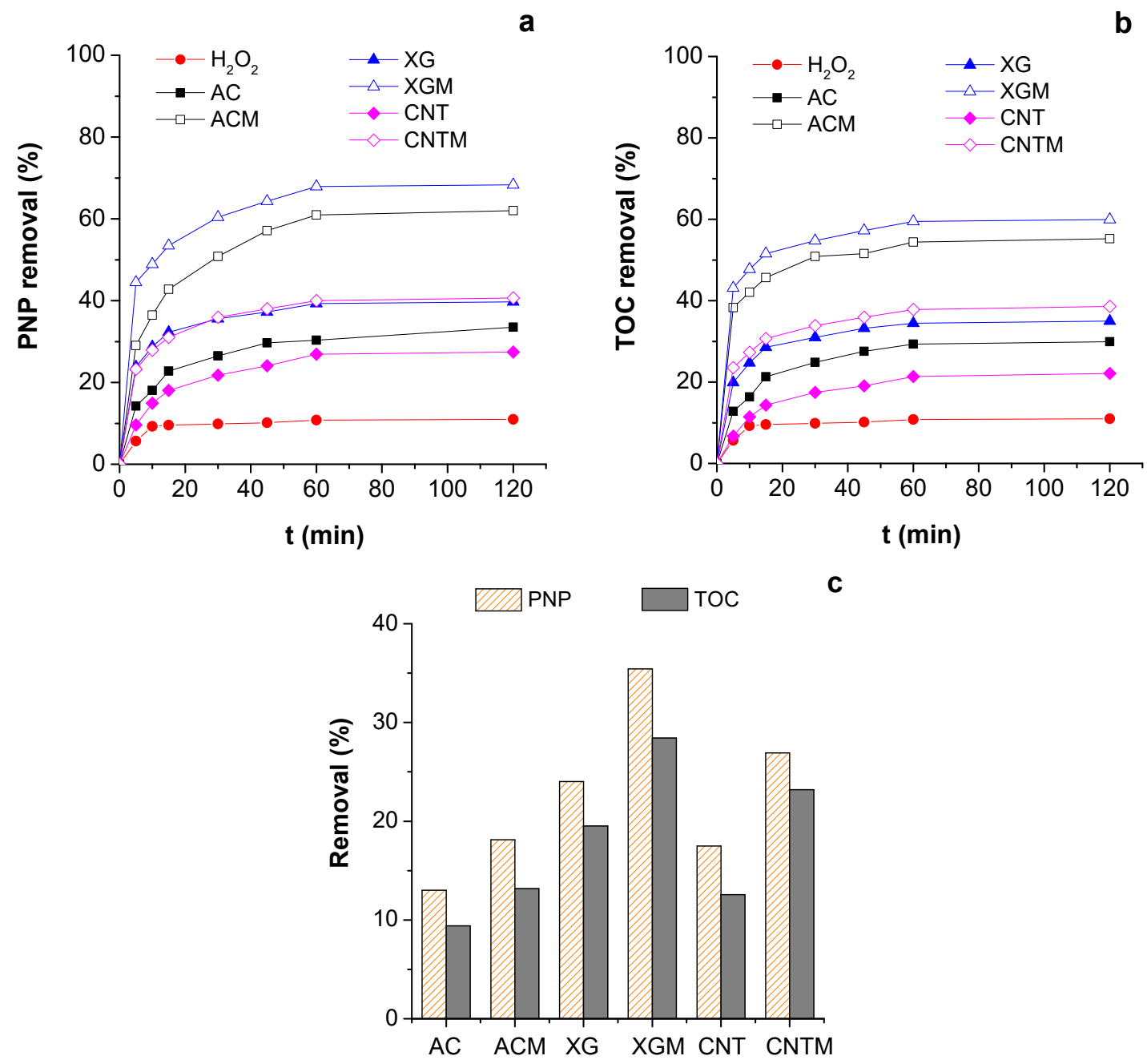

Figure 2. $p$-nitrophenol (PNP) (a) and total organic (TOC) (b) removal during catalytic wet peroxidation (CWPO) and adsorption, and PNP and TOC removals after $2 \mathrm{~h}$ for wet peroxidation only (c) using the carbon supports $\left(\mathrm{pH}=3.0, \mathrm{~T}=30{ }^{\circ} \mathrm{C}\right.$, [support] $=0.25 \mathrm{~g} \mathrm{~L}^{-1},\left[\mathrm{H}_{2} \mathrm{O}_{2}\right]=29 \mathrm{mmol} \mathrm{L}^{-1}$, $[\mathrm{PNP}]=3.6 \mathrm{mmol} \mathrm{L}^{-1}$ and $\mathrm{H}_{2} \mathrm{O}_{2}: \mathrm{PNP}$ molar ratio $=8.1$ ).

For all the carbon supports, the presence of $p$-benzoquinone, hydroquinone, and $p$-nitrocatechol (higher molecular weight intermediate by-products reported for PNP oxidation [43-45]) was not observed during the wet peroxidation experiments. Thus, the difference between the removal of PNP and TOC is probably due to the formation of short-chain carboxylic acids (the last intermediate compounds formed), which are more difficult to oxidize, and therefore remain in solution contributing for TOC. 

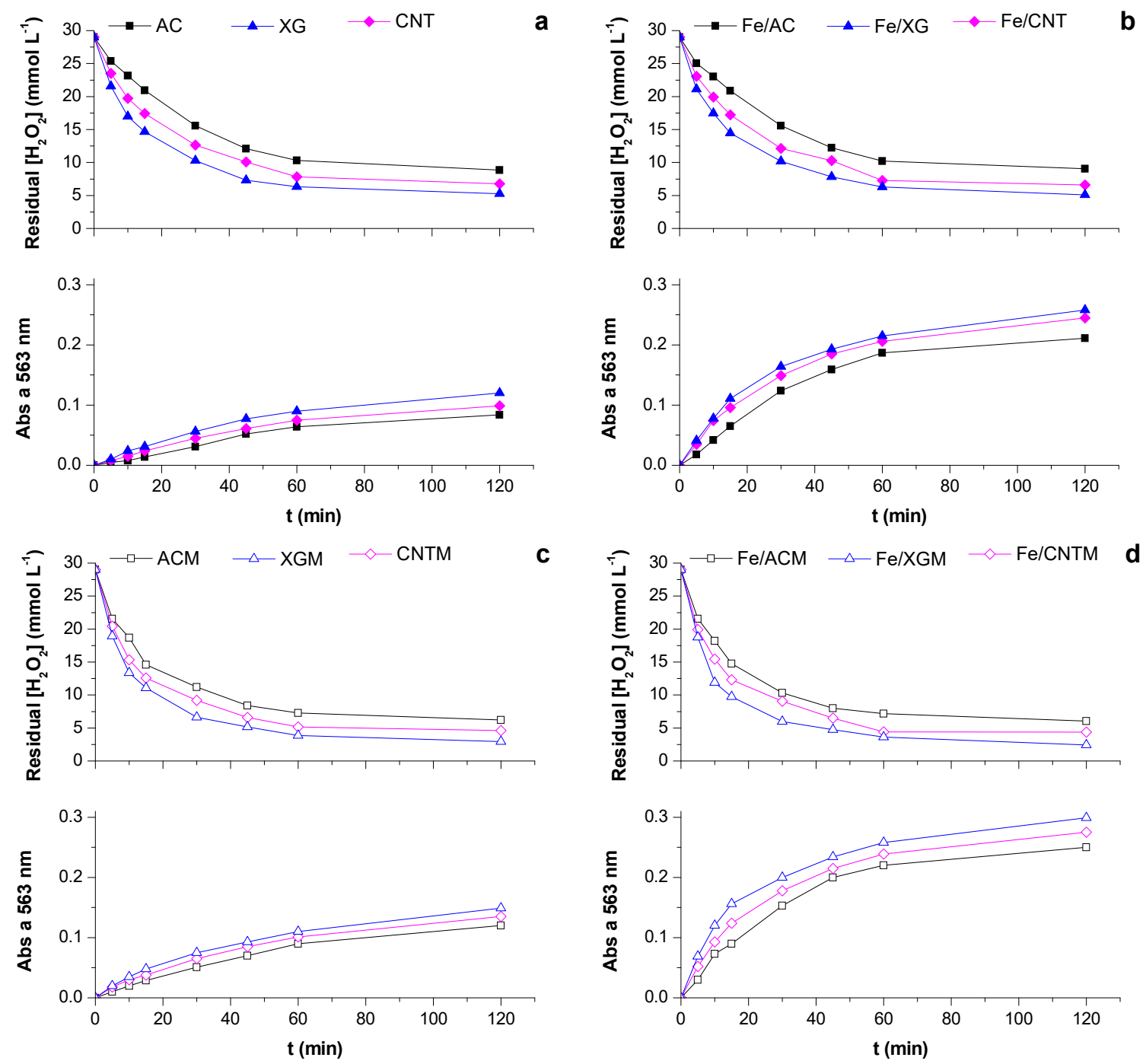

Figure 3. Consumption of hydrogen peroxide and hydroxyl radicals formation as a function of time for experiments with the supports (a) or with the iron supported catalysts (b) and supports (c) or catalysts $(\mathbf{d}) \mathrm{N}$-doped with melamine $\left(\mathrm{pH}=3.0, \mathrm{~T}=30^{\circ} \mathrm{C}\right.$, [support or catalyst] $=0.25 \mathrm{~g} \mathrm{~L}^{-1}$, $\left[\mathrm{H}_{2} \mathrm{O}_{2}\right]=29 \mathrm{mmol} \mathrm{L}^{-1}$ and $\left.[\mathrm{PNP}]=0 \mathrm{mmol} \mathrm{L}^{-1}\right)$.

\subsection{Fenton Reaction}

The different supports were impregnated with 2.0 wt.\% of iron (Fe/AC, Fe/CNT, Fe/XG, $\mathrm{Fe} / \mathrm{ACM}, \mathrm{Fe} / \mathrm{CNTM}$, and Fe/XGM) in order to assess its effect in PNP and TOC removal. Figure 4 reveals that both textural and chemical properties play an important role in the oxidative process. The evolution of PNP and TOC removals clearly indicates that high mesoporosity combined with high surface area benefit the process, which is in agreement with results shown in Figure $3 \mathrm{~b}$ that evidence a high amount of hydroxyl radicals formed. The Fe/XG sample, which is the catalyst with the highest $S_{\text {meso }}$ and intermediate $S_{B E T}$ (see Table 1$)$, presents the best performance $(41.7 \%$ and $45.4 \%$ for TOC and PNP removals, respectively), followed by the Fe/AC catalyst that has the larger $S_{B E T}$ but with a low $S_{\text {meso }}$, proceeded by the Fe/CNT catalyst which is the support with the lowest $S_{B E T}$, although being a mesoporous material. Nevertheless, taking into account the fact that adsorption occurs simultaneously with Fenton reaction, this phenomenon was suppressed in order to assess the improvement achieved in the heterogeneous Fenton conditions. Figure $4 \mathrm{c}$ shows that a change in the trend of PNP and TOC removal improvements can be observed. Fe/XG catalyst remains the one with highest performance, 
followed by $\mathrm{Fe} / \mathrm{CNT}$ and $\mathrm{Fe} / \mathrm{AC}$, this trend being similar to those observed in hydroxyl radicals formation and hydrogen peroxide consumption (see Figure $3 \mathrm{~b}$ ).
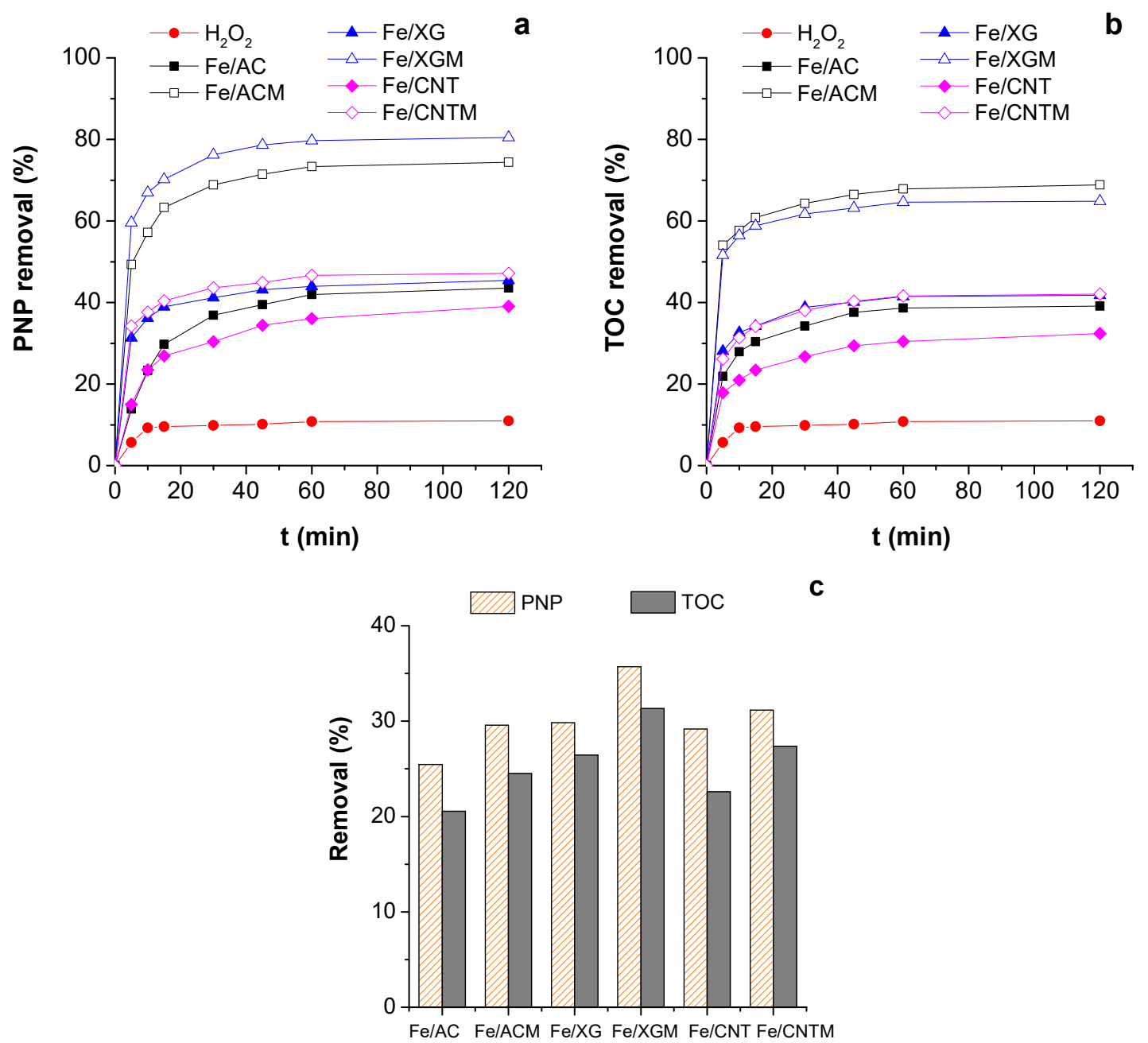

Figure 4. $p$-nitrophenol (PNP) (a) and total organic (TOC) (b) removal during Fenton's reaction and adsorption, and PNP and TOC removal, after $2 \mathrm{~h}$, for Fenton reaction only (c) with the Fe-containing catalysts $\left(\mathrm{pH}=3.0, \mathrm{~T}=30^{\circ} \mathrm{C}\right.$, [catalyst $]=0.25 \mathrm{~g} \mathrm{~L}^{-1},\left[\mathrm{H}_{2} \mathrm{O}_{2}\right]=29 \mathrm{mmol} \mathrm{L}^{-1},[\mathrm{PNP}]=3.6 \mathrm{mmol} \mathrm{L}^{-1}$ and $\mathrm{H}_{2} \mathrm{O}_{2}: \mathrm{PNP}$ molar ratio $=8.1$ ).

A considerable increase in the performances was observed when catalysts containing $\mathrm{N}$-groups on the carbon surface were used, also highlighting the importance of the surface chemistry in the Fenton reaction. The same tendency was reported by Messele et al. [36] when evaluating the degradation of phenol by carbon xerogels doped with nitrogen and impregnated with zero-valent iron. The main reason for the process efficiency increase is related to the presence of $\mathrm{N}$-functionalities on the carbon surface that increased the carbon basicity and, consequently, the content of electron rich sites on carbon basal planes, which increases the adsorption of the PNP besides promoting the easy access of the oxidant to the iron species that favors the hydroxyl radicals formation [38]. This fact was corroborated by the highest formation of hydroxyl radicals in blank runs with $\mathrm{N}$-doped catalysts when compared with undoped catalysts (see Figure 3b,d). Figure 4 shows that the N-doped catalysts present the same trend as the undoped catalysts.

The PNP and TOC removals achieved by the Fenton process (in the ranges of $\sim 43-80 \%$ and $32-69 \%$, respectively) were slightly higher than the CWPO with the carbon supports (in the ranges of $\sim 27-68 \%$ and $\sim 22-60 \%$, respectively). This is due to the fact that in the first process the formation of hydroxyl 
radicals occurs by: (i) decomposition of $\mathrm{H}_{2} \mathrm{O}_{2}$ on the carbon surface through Equation (6) [46] (which also occurs in the CWPO) and (ii) reaction between iron and oxidant (Equation (1) [7]). Experiments carried out in presence of a radical scavenging agent (dimethyl sulfoxide (DMSO) in a molar ratio of 1:10 to the oxidant) (see Figure S2 in the Supporting Information section) confirmed the occurrence of radical-mediated surface reactions because PNP and TOC removals obtained in these experiments were identical to those reached by simple adsorption. Other authors also reported that the presence of iron on carbon supports improves the degradation of organic compounds by oxidation $[17,20,36,38,47]$.

Again, high molecular weight intermediate compounds (such as hydroquinone, $p$-benzoquinone, and $p$-nitrocatechol) were not detected in solution, so the differences between the PNP and TOC removals are probably due to the formation of refractory low molecular weight carboxylic acids during the reaction that remain in solution and contribute for TOC.

The results obtained show that both textural and chemical properties of the carbon-based materials had an important role in Fenton oxidation, where high mesoporosity combined with high surface area and $\mathrm{N}$-functionalities improve their catalytic performance.

\subsection{Supports and Catalysts Stability and Reusability}

The stability and reusability of all the $\mathrm{N}$-doped supports and Fe-containing catalysts were also evaluated. For that, three consecutive reaction runs were performed under the same operating conditions evaluating the PNP and TOC removals and iron leached in solution. At the end of each run, the supports and catalysts were recovered by filtration and reused in the next run after drying at $40^{\circ} \mathrm{C}$ during 1 day.

Regarding the supports, it can be seen in Figure 5 that: (i) the performance of ACM decreases during the reutilization cycles, and (ii) for XGM and CNTM there is a great decrease in PNP and TOC removals from the first to the second cycle and a slight decrease to the third cycle. The decrease in efficiency of CWPO between reutilizations can be due to the porosity blocking and/or deactivation of carbons due to the oxidation of the carbon surface by the hydrogen peroxide, forming oxygen surface groups that have a negative influence in the electronic interactions between the carbon surface and PNP or other organic compounds. This deactivation of carbons was also reported in literature by other authors $[25,48,49]$.
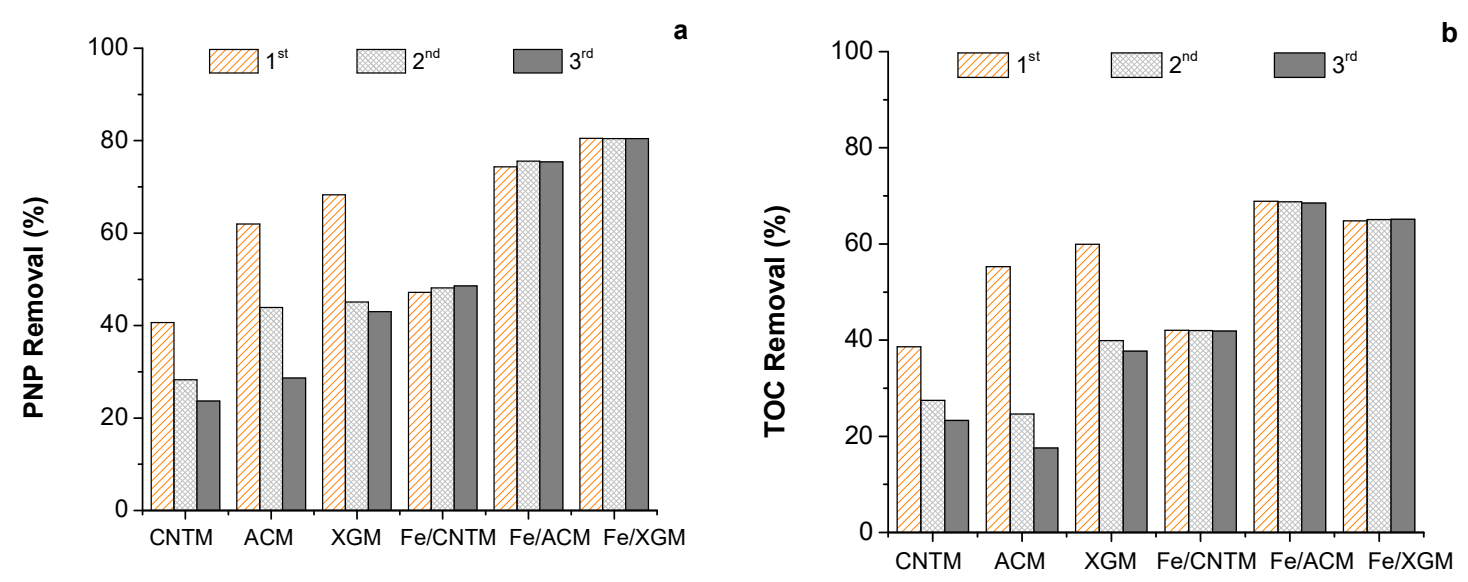

Figure 5. p-nitrophenol (PNP) (a) and total organic (TOC) (b) removal, after $2 \mathrm{~h}$, in subsequent cycles during wet peroxidation and adsorption with the carbon supports or Fenton's reaction and adsorption with the iron-containing catalysts $\left(\mathrm{pH}=3.0, \mathrm{~T}=30^{\circ} \mathrm{C}\right.$, [ support] $=0.25 \mathrm{~g} \mathrm{~L}^{-1},\left[\mathrm{H}_{2} \mathrm{O}_{2}\right]=29 \mathrm{mmol} \mathrm{L}^{-1}$, $[\mathrm{PNP}]=3.6 \mathrm{mmol} \mathrm{L}^{-1}$ and $\mathrm{H}_{2} \mathrm{O}_{2}: \mathrm{PNP}$ molar ratio $=8.1$ ).

On the other hand, no deactivation was observed when iron supported catalysts were used (see Figure 5), being the maximum variations between the three cycles, after $2 \mathrm{~h}$ of reaction, inferior to $1.4 \%$ and $0.3 \%$ for PNP and TOC removals, respectively. In addition, the iron concentration in 
solution was lower than the detection limit $(0.28 \mathrm{mg} / \mathrm{L})$ for all runs. Iron in solution was still not detected in additional experiments where a dose of catalyst 10 times higher was used, indicating that no iron leaching occurs (at least it is below the detection limit, which would correspond to $0.56 \mathrm{wt} . \%$ ); consequently, the catalysts were stable, which is a crucial aspect for application at industrial scale.

\subsection{Effect of Nitrogen Content}

In order to evaluate the effect of the nitrogen content on the efficiency of the processes, new experiments were performed using a carbon xerogel doped with urea -XGU and Fe/XGU-, since carbon xerogel is shown to be the best support and urea allows the introduction of lower N-content than melamine. The carbon xerogel supports present similar textural properties but different $\mathrm{N}$-content: XGM presents the highest $\mathrm{N}$-amount among the $\mathrm{N}$-doped supports, whereas XG does not contain nitrogen (see Table 2). XGM and XGU present the same type of N-groups, N-6 and N-5 structures. Figure $6 a, b$ show that the XGU support presents an intermediate performance between $X G$ and XGM during adsorption and CWPO, respectively; the same trend was observed when iron supported catalysts were applied in Fenton reaction (Figure 6c). This trend demonstrates that the N-content has an important role in the PNP and TOC removal, their performance being favored by the presence of higher amounts of $\mathrm{N}$, which must be due to the increase of hydroxyl radicals formed. In fact, Figure 7 shows that the formation of hydroxyl radicals increases in the presence of samples with higher $\mathrm{N}$-content, which is in line with other works $[17,38]$.

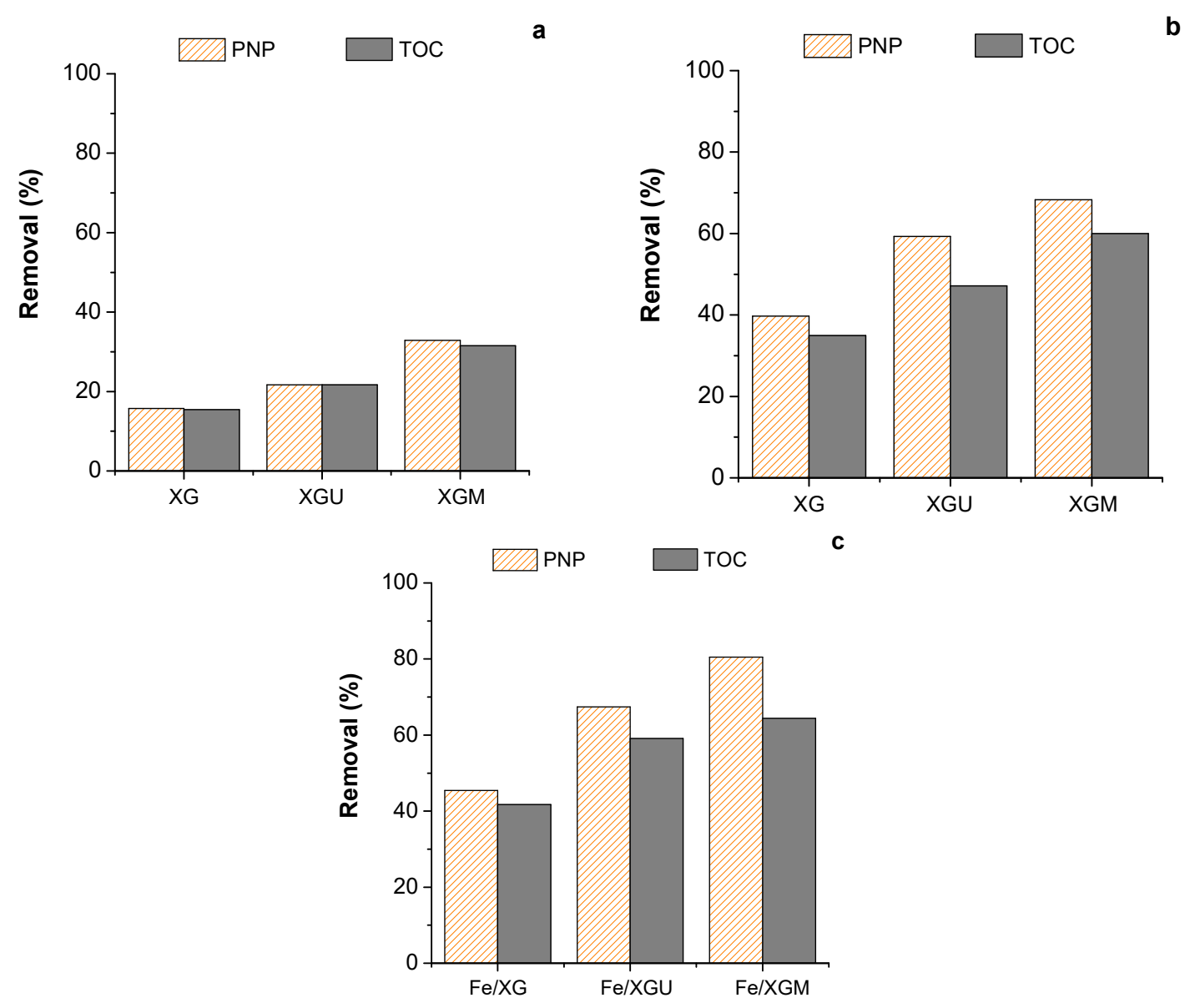

Figure 6. $p$-nitrophenol (PNP) and total organic (TOC) removal after $2 \mathrm{~h}$ of adsorption (a) and reaction (b) with support carbon xerogels (XG, XGU and XGM) and Fenton's reaction (c) using catalysts $(\mathrm{Fe} / \mathrm{XG}, \mathrm{Fe} / \mathrm{XGU}$ and $\mathrm{Fe} / \mathrm{XGM})\left(\mathrm{pH}=3.0, \mathrm{~T}=30{ }^{\circ} \mathrm{C}\right.$, [support or catalyst] $=0.25 \mathrm{~g} \mathrm{~L}^{-1}$, $\left[\mathrm{H}_{2} \mathrm{O}_{2}\right]_{\text {when used }}=29 \mathrm{mmol} \mathrm{L}^{-1},[\mathrm{PNP}]=3.6 \mathrm{mmol} \mathrm{L}{ }^{-1}$ and $\mathrm{H}_{2} \mathrm{O}_{2}: \mathrm{PNP}$ molar ratio $=8.1$, when $\mathrm{H}_{2} \mathrm{O}_{2}$ was used). 

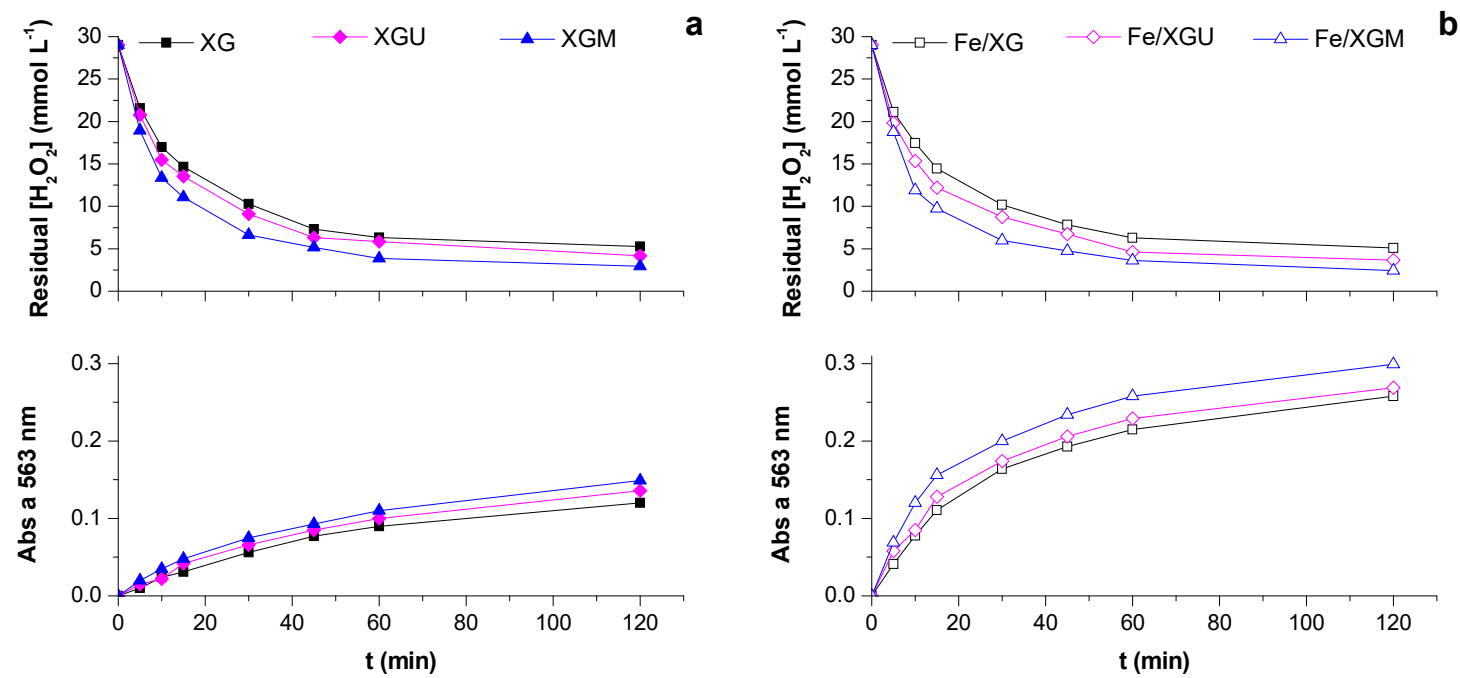

Figure 7. Consumption of hydrogen peroxide and hydroxyl radicals formation as a function of time for blank reaction with supports-xerogel (XG), XGU and XGM (a) and with catalysts -Fe/XG, Fe/XGU and $\mathrm{Fe} / \mathrm{XGM}(\mathbf{b})\left(\mathrm{pH}=3.0, \mathrm{~T}=30^{\circ} \mathrm{C}\right.$, [support or catalyst] $=0.25 \mathrm{~g} \mathrm{~L}^{-1},\left[\mathrm{H}_{2} \mathrm{O}_{2}\right]=29 \mathrm{mmol} \mathrm{L}^{-1}$, $\left.[\mathrm{PNP}]_{\text {blank run }}=0 \mathrm{mmol} \mathrm{L}^{-1}\right)$.

A close to linear correlation between the PNP removal after $2 \mathrm{~h}$ with the $\mathrm{N}$-content of $\mathrm{XG}, \mathrm{XGM}$, and XGU supports was found (determination coefficient $\left(r^{2}\right)>0.98$; Figure S3—see Supplementary Materials), demonstrating the relationship between the nitrogen content and catalytic performance of the materials. The carbon xerogel with the highest $\mathrm{N}$-content presents the highest catalytic activity.

\subsection{Evaluation of Intermediates Compounds Formed during the Heterogeneous Fenton Reaction}

The maximum mineralization achieved in the Fenton process was $16 \%$ lower than the PNP removal for the catalyst with the best catalytic performance -Fe/XGM- indicating that some intermediate compounds formed during the oxidative process remain in solution. Thus, a new run was carried out in the presence of this catalyst in order to assess the presence of these organic compounds and their contribution to TOC. Figure 8 a shows that in the first $30 \mathrm{~min}$ of reaction the PNP concentration decreased quickly; then its degradation rate slowed down until $60 \mathrm{~min}$, leaving its concentration practically constant afterwards; overall conversion was $80.3 \%$. The mineralization achieved, after $120 \mathrm{~min}$ of reaction, was $64.7 \%$-see Table 3 . The removals achieved were very similar to those obtained previously.

Table 3. $p$-nitrophenol (PNP) and carboxylic acids concentration along the reaction time under optimized conditions with Fe/XGM as catalyst, total carbon based on such analyzed compounds, experimental total organic carbon (TOC) and carbon balance.

\begin{tabular}{|c|c|c|c|c|c|c|c|}
\hline$t(\min )$ & $\begin{array}{c}\text { PNP } \\
\left(\mathrm{mgC} \mathrm{L}^{-1}\right)\end{array}$ & $\begin{array}{c}\text { Pyruvic } \\
\left(\mathrm{mgC} \mathrm{L}^{-1}\right)\end{array}$ & $\begin{array}{c}\text { Maleic } \\
\left(\mathrm{mgC} \mathrm{L}^{-1}\right)\end{array}$ & $\begin{array}{c}\text { Oxalic } \\
\left(\mathrm{mgC} \mathrm{L}^{-1}\right)\end{array}$ & $\begin{array}{l}\text { Total Carbon * } \\
\left(\mathrm{mgC} \mathrm{L}^{-1}\right)\end{array}$ & $\begin{array}{c}\text { TOC } \\
\left(\mathrm{mgC} \mathrm{L}^{-1}\right)\end{array}$ & $\begin{array}{c}\text { Contribution } \\
* *(\%)\end{array}$ \\
\hline 0 & 260.7 & 0.0 & 0.0 & 0.0 & 260.7 & 260.9 & 99.9 \\
\hline 5 & 105.3 & 7.3 & 6.4 & 5.1 & 124.1 & 126.3 & 98.3 \\
\hline 10 & 86.3 & 9.0 & 8.6 & 6.3 & 110.1 & 112.4 & 98.0 \\
\hline 15 & 78.0 & 11.0 & 10.9 & 7.5 & 107.5 & 107.3 & 100.2 \\
\hline 30 & 62.1 & 13.9 & 12.8 & 11.0 & 99.9 & 100.8 & 99.1 \\
\hline 45 & 55.6 & 13.0 & 12.0 & 13.9 & 94.5 & 94.6 & 99.9 \\
\hline 60 & 52.7 & 12.5 & 11.8 & 13.1 & 90.1 & 92.8 & 97.1 \\
\hline 120 & 50.9 & 12.4 & 11.7 & 13.0 & 87.4 & 92.2 & 95.5 \\
\hline
\end{tabular}

\footnotetext{
* Total carbon assessed from the sum of the identified compounds; ** Ratio between Total carbon and TOC $\times 100$
} 


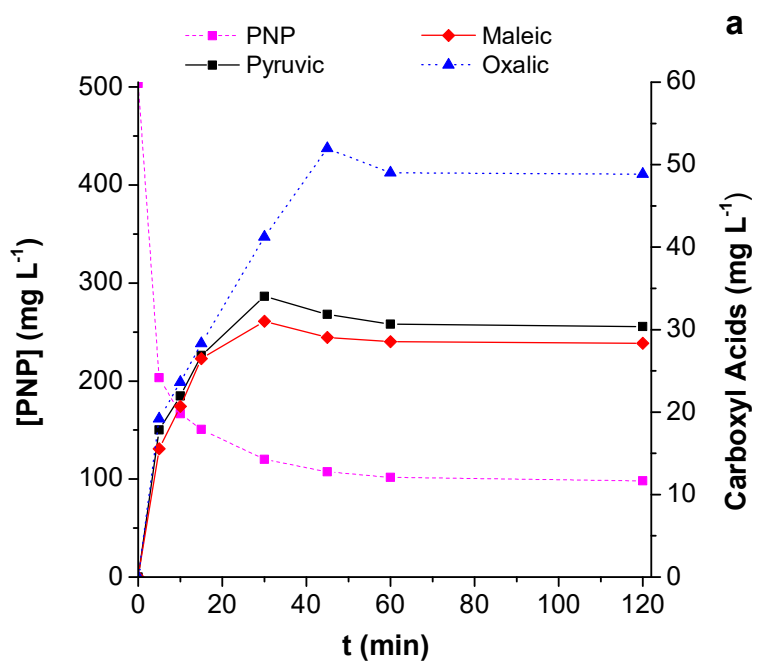

a

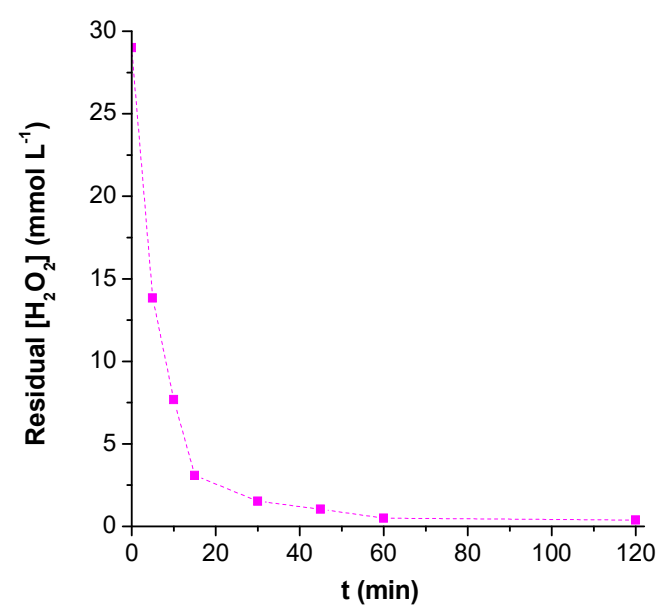

Figure 8. $p$-nitrophenol (PNP) and carboxylic acids concentration (a) and consumption of hydrogen peroxide (b) along Fenton reaction with Fe/XGM catalyst $\left(\mathrm{pH}=3.0, \mathrm{~T}=30^{\circ} \mathrm{C},[\mathrm{Fe} / \mathrm{XGM}]=0.25 \mathrm{~g} \mathrm{~L}^{-1}\right.$, $\left[\mathrm{H}_{2} \mathrm{O}_{2}\right]=29 \mathrm{mmol} \mathrm{L}^{-1},[\mathrm{PNP}]=3.6 \mathrm{mmol} \mathrm{L}^{-1}$ and $\mathrm{H}_{2} \mathrm{O}_{2}: \mathrm{PNP}$ molar ratio $=8.1$ ).

Again, hydroquinone, $p$-benzoquinone, and $p$-nitrocatechol were not detected in the solution, indicating that their degradation into carboxylic acids is fast. This fact was corroborated by the carbon balance, which was higher than $95 \%$-see Table 3. The absence of such compounds was also observed in another work where PNP has been degraded by the heterogeneous Fenton process catalyzed with activated carbon doped with melamine and impregnated with iron [17]. The presence of carboxylic acids in solution was observed and the concentrations of pyruvic, maleic, and oxalic acids is shown in Figure 8a. Their formation increased in the first $30 \mathrm{~min}$ of reaction, which corresponds to the time where a higher decrease of the PNP concentration occurs. Afterwards the concentration of pyruvic and maleic acids decreased due to their oxidation into oxalic acid, as proposed by other authors [17,44]. From 45 to $60 \mathrm{~min}$ of reaction, the concentration of oxalic decreased slightly due to its degradation into carbon dioxide and water. For reaction times higher than $60 \mathrm{~min}$ the concentration of carboxylic acids remains constant (corresponding also to the absence of PNP oxidation) indicating the cessation of the oxidation reactions; this is corroborated by the total consumption of the oxidant (see Figure 8b).

\section{Materials and Methods}

\subsection{Materials}

PNP was purchased from Fluka (reagent grade, CAS: 100-02-7). The oxidant $\left(30 \%(w / v) \mathrm{H}_{2} \mathrm{O}_{2}\right.$ aqueous solution) used in this work was analytical reagent grade supplied by Fluka. The sulfuric acid (95-97\%) and nitric acid (65\%) were obtained from Panreac and the sodium hydroxide (99\%) was purchased from Merck. Resorcinol (99\%) and formaldehyde solution (37\%) were purchased from Sigma-Aldrich. Melamine $(\geq 99 \%)$ and urea $(99.5 \%)$ were obtained from Fluka and Acros Organics, respectively.

\subsection{Carbon-Based Materials Preparation and Characterization}

Nitrogen-free and nitrogen-doped carbon-based materials with different textural properties were used. For that, commercial NORIT GAC 1240 PLUS activated carbon, commercial Nanocyl NC 3100 multiwalled carbon nanotubes, as well as a carbon xerogel, were used as starting materials.

Initially, the activated carbon was ground with a mortar and sieved to a particle diameter lower than $0.1 \mathrm{~mm}$. Then, sample AC and sample CNT were doped with nitrogen using melamine (M) as precursor. For that, $0.6 \mathrm{~g}$ of the original AC and CNT was dipped into $50 \mathrm{~mL}$ of a $1 \mathrm{~mol} \mathrm{~L}^{-1}$ aqueous solution of melamine, and stirred at room temperature during $24 \mathrm{~h}$. Thereafter, the samples (ACM and 
CNTM) were filtered, washed with distilled water and dried in an oven at $110^{\circ} \mathrm{C}$ overnight. These samples were heat treated at $600{ }^{\circ} \mathrm{C}$ during $1 \mathrm{~h}$ under nitrogen flow.

The $\mathrm{XG}$ was prepared at $\mathrm{pH} 6.9$ by the conventional sol-gel method, using the polycondensation of resorcinol and formaldehyde as described elsewhere [50]. Briefly, $25 \mathrm{~g}$ of resorcinol were mixed with $40 \mathrm{~mL}$ of distilled water under magnetic stirring. Then, the $\mathrm{pH}$ was adjusted to 6.9 and a few drops of $2 \mathrm{~mol} \mathrm{~L}^{-1} \mathrm{NaOH}$ were added, followed by the addition of $34 \mathrm{~mL}$ of formaldehyde solution and the final $\mathrm{pH}$ was adjusted to 6.9 by addition of $0.1 \mathrm{~mol} \mathrm{~L}^{-1} \mathrm{HCl}$. The gelation was achieved in a water bath at $85^{\circ} \mathrm{C}$ during 3 days. After this step, the gel was crushed and dried in an oven for 4 days: 1 st day at $60^{\circ} \mathrm{C}, 2$ nd day at $80^{\circ} \mathrm{C}, 3$ rd day at $100{ }^{\circ} \mathrm{C}$, and 4 th day at $120^{\circ} \mathrm{C}$. The dried gel was carbonized under nitrogen flow $\left(100 \mathrm{~cm}^{3} \mathrm{STP} \mathrm{min}^{-1}\right)$ at constant heating rate of $2{ }^{\circ} \mathrm{C} \mathrm{min}^{-1}$, under the following conditions: (1) from room temperature to $200{ }^{\circ} \mathrm{C}$ and hold for $2 \mathrm{~h}$, (2) up to $300^{\circ} \mathrm{C}$ and hold for $1 \mathrm{~h}$, (3) up to $500{ }^{\circ} \mathrm{C}$ and hold for $2 \mathrm{~h}$, (4) up to $600^{\circ} \mathrm{C}$ and hold for $2 \mathrm{~h}$. Nitrogen-doped carbon xerogels were prepared using the protocol described elsewhere [51] adding melamine or urea (XGM and XGU, respectively) as nitrogen precursor during the synthesis. For that, $15 \mathrm{~g}$ of resorcinol and $3 \mathrm{~g}$ of melamine or $4 \mathrm{~g}$ of urea were mixed in $18 \mathrm{~mL}$ of distilled water and were heated up to $90{ }^{\circ} \mathrm{C}$ under stirring until melamine or urea was dissolved. After that, the solution was cooled until it reached room temperature and $20 \mathrm{~mL}$ of formaldehyde was added. The next steps were equal to those described to sample XG. All the carbon xerogel samples were ground to a particle size lower than $0.1 \mathrm{~mm}$.

Iron catalysts supported in all the carbon-based materials (Fe/y, where $\mathrm{y}$ is the carbon material used as support) were prepared by the incipient wetness impregnation method, which was always conducted under ultrasonic mixing. The precursor solution was added drop wise using a peristaltic pump and the slurry was left at room temperature under ultrasonic mixing for $90 \mathrm{~min}$. The precursor solution was prepared with iron (III) nitrate nonahydrate in order to obtain an iron load of $2 \mathrm{wt} . \%$; the iron content in the catalysts should be very similar to the theoretical one, as verified in previous works using the same methodology [52]. After impregnation, the samples were dried at $110^{\circ} \mathrm{C}$ overnight, heat treated at $400{ }^{\circ} \mathrm{C}$ during $1 \mathrm{~h}$ under nitrogen flow and reduced under hydrogen flow for $3 \mathrm{~h}$ at $400{ }^{\circ} \mathrm{C}$.

The carbon-based materials were characterized by $\mathrm{N}_{2}$ adsorption at $-196{ }^{\circ} \mathrm{C}$, by (EA, XPS, and by determination of $\mathrm{pH}_{\mathrm{PZC}}$. Further details about the techniques and conditions used can be found elsewhere [17].

\subsection{Adsorption and Reaction Tests}

The experiments were carried out in a stirred slurry batch reactor connected to a thermostatic bath (Hubber, polystat cc1) to maintain the temperature at $30 \pm 0.5^{\circ} \mathrm{C}$. Immediately after reaching the desired temperature, $200 \mathrm{~mL}$ of PNP solution $\left(3.6 \mathrm{mmol} \mathrm{L}^{-1}\right.$; a concentration typically found in industrial wastewater $[29,53]$ ) was adjusted to a $\mathrm{pH}$ of 3.0 (with $1 \mathrm{~mol} \mathrm{~L}^{-1} \mathrm{H}_{2} \mathrm{SO}_{4}$ ); then $0.25 \mathrm{~g} \mathrm{~L}^{-1}$ of support was added, this being considered the time zero for the adsorption runs. For oxidation experiments, immediately after adding the catalyst (Fenton's oxidation) or support (CWPO), $29 \mathrm{mmol} \mathrm{L}^{-1}$ of $30 \%(\mathrm{w} / \mathrm{v}) \mathrm{H}_{2} \mathrm{O}_{2}$ aqueous solution was also added, which corresponds to the initial reaction time $(\mathrm{t}=0)$ of such runs. The initial $\mathrm{pH}$ and concentration of hydrogen peroxide were fixed in the best operating conditions obtained previously [17]. The oxidant concentration used is smaller than the stoichiometric amount required for total degradation of PNP $\left(50 \mathrm{mmol} \mathrm{L}^{-1}\right)$ because the removal of PNP and formed intermediates/by-products is achieved by both adsorption and oxidation processes [17]. Constant stirring (at $200 \mathrm{rpm}$ ) was ensured by means of a bar and a magnetic plate (Falc).

Periodically, samples were taken from the reactor for measuring the PNP and total organic carbon (TOC) concentrations. Before analysis, the reaction was stopped by increasing the $\mathrm{pH}$ till 11 with $10 \mathrm{~mol} \mathrm{~L}^{-1} \mathrm{NaOH}$ followed by neutralization (to $\mathrm{pH} \sim 7.0$ ) with $1 \mathrm{~mol} \mathrm{~L}^{-1} \mathrm{H}_{2} \mathrm{SO}_{4}$, then the carbon-based materials were removed by filtration with a $0.2 \mu \mathrm{m}$ nylon syringe filter (from VWR). The residual hydrogen peroxide (after filtration) and iron (in case of Fenton's oxidation) concentrations in solution were measured, immediately (without stopping the reaction), at the end of the catalytic 
reactions runs. For assessing iron leaching, the samples were filtered through nylon filters with $0.45 \mu \mathrm{m}$ of porosity and acidified until $\mathrm{pH} \sim 1.0$ with concentrated nitric acid to keep the metal dissolved in solution.

The blank experiments-without PNP-were carried out with the goal of identifying the formation of hydroxyl radicals in solution; the tests proceeded in the same way as the catalytic runs, only the PNP solution was replaced by distilled water. Throughout the reactions, samples were taken and filtered, and then $\mathrm{H}_{2} \mathrm{O}_{2}$ concentration was measured and the presence of the hydroxyl radicals evaluated, as described in the following section.

\subsection{Analytical Methods}

Determination of the $p$-nitrophenol concentration and the evaluation of the presence of intermediate compounds, such as $p$-benzoquinone, hydroquinone, and $p$-nitrocatechol, were carried out by high pressure liquid chromatography (HPLC). TOC was measured in accordance with Method 5310 D [54] and was carried out in a Shimadzu TOC-L apparatus equipped with auto sampler (Shidmazu ASI-L). The hydrogen peroxide concentration was measured by the method developed by Sellers [55]. The formation of hydroxyl radicals was evaluated by the method proposed by Wang et al. [56]. The iron leached into the solution was measured by flame atomic absorption spectrometry (AAS)-Method 3111 B [54], using an AAS UNICAM spectrophotometer (model 939/959). The $\mathrm{pH}$ measurement was performed by potentiometric measurement (Method $4500 \mathrm{H}^{+}$[54]). Further details about any of the analytical methods can be found elsewhere [17].

All analytical determinations were performed in duplicate and the coefficients of variation were less than $2 \%$ for all parameters.

\section{Conclusions}

Different undoped and N-doped carbon-based materials were prepared, characterized, and used as adsorbents or catalysts. In addition, these carbon-based materials were impregnated with iron (load of $2 \mathrm{wt} . \%$ ) and used as catalysts in Fenton oxidation.

The textural properties of the carbon-based materials play an important role in the adsorption and/or catalytic activity. The support with the highest surface area -AC- presents the best performance during PNP adsorption, which is corroborated by the linear relationship between the PNP removal and the $S_{B E T}$ of the carbon-based materials. In contrast, the support or catalyst with the highest mesopores surface area -XG or Fe/XG- lead to the best removals by CWPO or Fenton's oxidation, respectively. On the other hand, the surface chemical properties also proved to be important in the performance of the materials, since the presence of $\mathrm{N}$-functionalities, mainly pyrrole and pyridinic groups, on the carbons surface increases the PNP and TOC removals in all processes studied. A linear relationship between the PNP removal and N-content of carbon xerogels was obtained.

The Fe/XGM catalyst shows the best performances for the Fenton process with removals of $81 \%$ for PNP and 65\% for TOC after $2 \mathrm{~h}$. Reaction products identified (pyruvic, maleic, and oxalic acids) accounted, together with residual PNP, for more than $95 \%$ of the TOC along the experiments.

Stability and reusability of supports and catalysts were confirmed by recycling experiments. It was shown that the carbon-based materials were deactivated by hydrogen peroxide; in contrast, the iron catalysts were very stable and presented low coefficients of variation for PNP (1.4\%) and TOC $(0.3 \%)$ removals in the 3 cycles of reuse and without iron leaching.

The results obtained show that both textural and chemical properties of the carbon-based materials play a relevant role in the Fenton oxidation, where high mesoporosity combined with high surface area and $\mathrm{N}$-functionalities improve their catalytic performance, demonstrating that carbon-based materials can be tailored to improve the efficiency of this advanced oxidation process. 
Supplementary Materials: The following are available online at http:/ /www.mdpi.com/2073-4344/9/3/258/s1, Figure S1: Correlation between specific surface area and the PNP removal after $2 \mathrm{~h}$ of adsorption with the carbon supports undoped (a) and N-doped with melamine (b) $\left(\mathrm{pH}=3.0, \mathrm{~T}=30^{\circ} \mathrm{C}\right.$, [support] $=0.25 \mathrm{~g} \mathrm{~L}^{-1}$ and $\left.[\mathrm{PNP}]=3.6 \mathrm{mmol} \mathrm{L}^{-1}\right)$. Figure S2: PNP (a) and TOC (b) removal after $2 \mathrm{~h}$ of adsorption or Fenton's oxidation in presence of DMSO with the catalysts $\left(\mathrm{pH}=3.0, \mathrm{~T}=30^{\circ} \mathrm{C}\right.$, [catalyst] $=0.25 \mathrm{~g} \mathrm{~L}^{-1},\left[\mathrm{H}_{2} \mathrm{O}_{2}\right]$ when used $=29 \mathrm{mmol} \mathrm{L}^{-1}$, $[\mathrm{PNP}]=3.6 \mathrm{mmol} \mathrm{L}^{-1}$ and $\mathrm{H}_{2} \mathrm{O}_{2}: \mathrm{PNP}$ molar ratio $=8.1$, when $\mathrm{H}_{2} \mathrm{O}_{2}$ was used). Figure S3: Relationship between PNP removal after $2 \mathrm{~h}$ of Fenton reaction and $\mathrm{N}$-amount of $\mathrm{N}$-doped xerogels $\left(\mathrm{pH}=3.0, \mathrm{~T}=30^{\circ} \mathrm{C}\right.$,

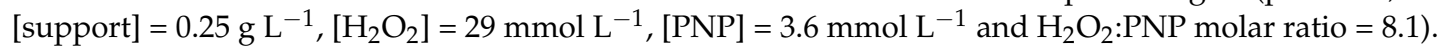

Author Contributions: Conceptualization, methodology and investigation, O.S.G.P.S. and C.S.R.D.; resources, L.M.M. and M.F.R.P.; writing-original draft preparation, O.S.G.P.S. and C.S.R.D.; writing-review and editing, L.M.M. and M.F.R.P. All authors discussed the results and commented on the manuscript.

Funding: This research was partially funded by project “AIProcMat@N2020_Advanced Industrial Processes and Materials for a Sustainable Northern Region of Portugal 2020", with the reference NORTE-01-0145-FEDER-000006, supported by Norte Portugal Regional Operational Programme (NORTE 2020), under the Portugal 2020 Partnership Agreement, through the European Regional Development Fund (ERDF), by Projects UID/EQU/00511/2019-Laboratory for Process Engineering, Environment, Biotechnology and Energy-LEPABE and by Associate Laboratory LSRE-LCM-UID/EQU/50020/2019 funded by national funds through FCT/MCTES (PIDDAC).

Acknowledgments: Carmen Rodrigues is grateful to FCT for financial support through the Postdoctoral grant (SFRH/BPD/115879/2016) with financing from National and the European Social Funds through the Human Capital Operational Programme (POCH).

Conflicts of Interest: The authors declare no conflict of interest.

\section{References}

1. Von Sonntag, C. Advanced oxidation processes: Mechanistic aspects. Water Sci. Technol. 2008, 58, $1015-1021$. [CrossRef] [PubMed]

2. Stasinakis, A.S. Use of selected advanced oxidation processes (aops) for wastewater treatment-A mini review. Glob. NEST J. 2008, 10, 376-385.

3. Laherty, K.A.; Huang, C.P. Continuous flow applications of fenton's reagent for the treatment of reafractory wastewater. In Proceedings of the Second International Symposium on Chemical Oxidation-Technologies for the Nineties, Nashville, TN, USA, 19-21 February 1992; CRC Press: Nashville, TN, USA, 1992.

4. Bigda, R.J. Consider fenton's chemistry for wastewater treatment. Chem. Eng. Prog. 1995, 91, 62-66.

5. Arslan, I.; Akmehmet Balcioglu, I.; Tuhkanen, T. Oxidative treatment of simulated dyehouse effluent by uv and near-uv light assisted fenton's reagent. Chemosphere 1999, 39, 2767-2783. [CrossRef]

6. Papadopoulos, A.E.; Fatta, D.; Loizidou, M. Development and optimization of dark fenton oxidation for the treatment of textile wastewaters with high organic load. J. Hazard. Mater. 2007, 146, 558-563. [CrossRef] [PubMed]

7. Walling, C. Fenton's reagent revisited. Acc. Chem. Res. 1975, 8, 125-131. [CrossRef]

8. Queirós, S.; Morais, V.; Rodrigues, C.S.D.; Maldonado-Hódar, F.J.; Madeira, L.M. Heterogeneous fenton's oxidation using fe/zsm-5 as catalyst in a continuous stirred tank reactor. Sep. Purif. Technol. 2015, 141, 235-245. [CrossRef]

9. Navalon, S.; Alvaro, M.; Garcia, H. Heterogeneous fenton catalysts based on clays, silicas and zeolites. Appl. Catal. B Environ. 2010, 99, 1-26. [CrossRef]

10. Herney-Ramirez, J.; Vicente, M.A.; Madeira, L.M. Heterogeneous photo-fenton oxidation with pillared clay-based catalysts for wastewater treatment: A review. Appl. Catal. B Environ. 2010, 98, 10-26. [CrossRef]

11. Garrido-Ramírez, E.G.; Theng, B.K.G.; Mora, M.L. Clays and oxide minerals as catalysts and nanocatalysts in fenton-like reactions-A review. Appl. Clay Sci. 2010, 47, 182-192. [CrossRef]

12. Sashkina, K.A.; Polukhin, A.V.; Labko, V.S.; Ayupov, A.B.; Lysikov, A.I.; Parkhomchuk, E.V. Fe-silicalites as heterogeneous fenton-type catalysts for radiocobalt removal from edta chelates. Appl. Catal. B Environ. 2016, 185, 353-361. [CrossRef]

13. Esteves, B.M.; Rodrigues, C.S.D.; Boaventura, R.A.R.; Maldonado-Hódar, F.J.; Madeira, L.M. Coupling of acrylic dyeing wastewater treatment by heterogeneous fenton oxidation in a continuous stirred tank reactor with biological degradation in a sequential batch reactor. J. Environ. Manag. 2016, 166, 193-203. [CrossRef] 
14. Duarte, F.; Maldonado-Hódar, F.J.; Madeira, L.M. New insight about orange ii elimination by characterization of spent activated carbon/fe fenton-like catalysts. Appl. Catal. B Environ. 2013, 129, 264-272. [CrossRef]

15. Menéndez, J.A.; Phillips, J.; Xia, B.; Radovic, L.R. On the modification and characterization of chemical surface properties of activated carbon: In the search of carbons with stable basic properties. Langmuir 1996, 12, 4404-4410. [CrossRef]

16. Auer, E.; Freund, A.; Pietsch, J.; Tacke, T. Carbons as supports for industrial precious metal catalysts. Appl. Catal. A Gen. 1998, 173, 259-271. [CrossRef]

17. Rodrigues, C.S.D.; Soares, O.S.G.P.; Pinho, M.T.; Pereira, M.F.R.; Madeira, L.M. P-nitrophenol degradation by heterogeneous fenton's oxidation over activated carbon-based catalysts. Appl. Catal. B Environ. 2017, 219, 109-122. [CrossRef]

18. Liu, X.; Yin, H.; Lin, A.; Guo, Z. Effective removal of phenol by using activated carbon supported iron prepared under microwave irradiation as a reusable heterogeneous fenton-like catalyst. J. Environ. Chem. Eng. 2017, 5, 870-876. [CrossRef]

19. Ramirez, J.H.; Maldonado-Hódar, F.J.; Pérez-Cadenas, A.F.; Moreno-Castilla, C.; Costa, C.A.; Madeira, L.M. Azo-dye orange ii degradation by heterogeneous fenton-like reaction using carbon-fe catalysts. Appl. Catal. B Environ. 2007, 75, 312-323. [CrossRef]

20. Messele, S.A.; Soares, O.S.G.P.; Órfão, J.J.M.; Bengoa, C.; Stüber, F.; Fortuny, A.; Fabregat, A.; Font, J. Effect of activated carbon surface chemistry on the activity of zvi/ac catalysts for fenton-like oxidation of phenol. Catal. Today 2015, 240, 73-79. [CrossRef]

21. Cleveland, V.; Bingham, J.-P.; Kan, E. Heterogeneous fenton degradation of bisphenol a by carbon nanotube-supported $\mathrm{Fe}_{3} \mathrm{O}_{4}$. Sep. Purif. Technol. 2014, 133, 388-395. [CrossRef]

22. Yao, Y.; Chen, H.; Lian, C.; Wei, F.; Zhang, D.; Wu, G.; Chen, B.; Wang, S. Fe, Co, Ni nanocrystals encapsulated in nitrogen-doped carbon nanotubes as fenton-like catalysts for organic pollutant removal. J. Hazard. Mater. 2016, 314, 129-139. [CrossRef]

23. Arshadi, M.; Abdolmaleki, M.K.; Mousavinia, F.; Khalafi-Nezhad, A.; Firouzabadi, H.; Gil, A. Degradation of methyl orange by heterogeneous fenton-like oxidation on a nano-organometallic compound in the presence of multi-walled carbon nanotubes. Chem. Eng. Res. Des. 2016, 112, 113-121. [CrossRef]

24. Carrasco-Díaz, M.R.; Castillejos-López, E.; Cerpa-Naranjo, A.; Rojas-Cervantes, M.L. On the textural and crystalline properties of fe-carbon xerogels. Application as fenton-like catalysts in the oxidation of paracetamol by $\mathrm{H}_{2} \mathrm{O}_{2}$. Microporous Mesoporous Mater. 2017, 237, 282-293. [CrossRef]

25. Pinho, M.T.; Gomes, H.T.; Ribeiro, R.S.; Faria, J.L.; Silva, A.M.T. Carbon nanotubes as catalysts for catalytic wet peroxide oxidation of highly concentrated phenol solutions: Towards process intensification. Appl. Catal. B Environ. 2015, 165, 706-714. [CrossRef]

26. Alegre, C.; Calvillo, L.; Moliner, R.; González-Expósito, J.A.; Guillén-Villafuerte, O.; Huerta, M.V.M.; Pastor, E.; Lázaro, M.J. Pt and ptru electrocatalysts supported on carbon xerogels for direct methanol fuel cells. J. Power Sources 2011, 196, 4226-4235. [CrossRef]

27. ATSDR. Toxicological Profile for Nitrophenols: 2-Nitrophenol and 4-Nitrophenol; Public Agency for Toxic Substances and Disease Registry, Health Service: Atlanta, GA, USA, 1992.

28. Tang, L.; Tang, J.; Zeng, G.; Yang, G.; Xie, X.; Zhou, Y.; Pang, Y.; Fang, Y.; Wang, J.; Xiong, W. Rapid reductive degradation of aqueous p-nitrophenol using nanoscale zero-valent iron particles immobilized on mesoporous silica with enhanced antioxidation effect. Appl. Surf. Sci. 2015, 333, 220-228. [CrossRef]

29. Ji, Q.; Li, J.; Xiong, Z.; Lai, B. Enhanced reactivity of microscale Fe/Cu bimetallic particles (Mfe/Cu) with persulfate (ps) for p-nitrophenol (pnp) removal in aqueous solution. Chemosphere 2017, 172, 10-20. [CrossRef]

30. Zhang, A.; Wang, N.; Zhou, J.; Jiang, P.; Liu, G. Heterogeneous fenton-like catalytic removal of p-nitrophenol in water using acid-activated fly ash. J. Hazard. Mater. 2012, 201-202, 68-73. [CrossRef]

31. Subbulekshmi, N.L.; Subramanian, E. Nano CuO immobilized fly ash zeolite fenton-like catalyst for oxidative degradation of p-nitrophenol and p-nitroaniline. J. Environ. Chem. Eng. 2017, 5, 1360-1371. [CrossRef]

32. Zhong, Y.; Liang, X.; He, Z.; Tan, W.; Zhu, J.; Yuan, P.; Zhu, R.; He, H. The constraints of transition metal substitutions (Ti, Cr, Mn, Co and Ni) in magnetite on its catalytic activity in heterogeneous fenton and uv/fenton reaction: From the perspective of hydroxyl radical generation. Appl. Catal. B Environ. 2014, 150-151, 612-618. [CrossRef] 
33. Ferroudj, N.; Nzimoto, J.; Davidson, A.; Talbot, D.; Briot, E.; Dupuis, V.; Bée, A.; Medjram, M.S.; Abramson, S. Maghemite nanoparticles and maghemite/silica nanocomposite microspheres as magnetic fenton catalysts for the removal of water pollutants. Appl. Catal. B Environ. 2013, 136-137, 9-18. [CrossRef]

34. Wan, D.; Li, W.; Wang, G.; Lu, L.; Wei, X. Degradation of p-nitrophenol using magnetic fe0/fe3o4/coke composite as a heterogeneous fenton-like catalyst. Sci. Total Environ. 2017, 574, 1326-1334. [CrossRef]

35. Ribeiro, R.S.; Silva, A.M.T.; Figueiredo, J.L.; Faria, J.L.; Gomes, H.T. Removal of 2-nitrophenol by catalytic wet peroxide oxidation using carbon materials with different morphological and chemical properties. Appl. Catal. B Environ. 2013, 140, 356-362. [CrossRef]

36. Messele, S.A.; Soares, O.S.G.P.; Órfão, J.J.M.; Bengoa, C.; Font, J. Zero-valent iron supported on nitrogen-doped carbon xerogel as catalysts for the oxidation of phenol by fenton-like system. Environ. Technol. 2018, 39, 2951-2958. [CrossRef]

37. Dhaouadi, A.; Adhoum, N. Heterogeneous catalytic wet peroxide oxidation of paraquat in the presence of modified activated carbon. Appl. Catal. B Environ. 2010, 97, 227-235. [CrossRef]

38. Messele, S.A.; Soares, O.S.G.P.; Órfão, J.J.M.; Stüber, F.; Bengoa, C.; Fortuny, A.; Fabregat, A.; Font, J. Zero-valent iron supported on nitrogen-containing activated carbon for catalytic wet peroxide oxidation of phenol. Appl. Catal. B Environ. 2014, 154, 329-338. [CrossRef]

39. Yang, G.; Chen, H.; Qin, H.; Feng, Y. Amination of activated carbon for enhancing phenol adsorption: Effect of nitrogen-containing functional groups. Appl. Surf. Sci. 2014, 293, 299-305. [CrossRef]

40. Santos, V.P.; Pereira, M.F.R.; Faria, P.C.C.; Órfão, J.J.M. Decolourisation of dye solutions by oxidation with $\mathrm{H}_{2} \mathrm{O}_{2}$ in the presence of modified activated carbons. J. Hazard. Mater. 2009, 162, 736-742. [CrossRef]

41. Sun, H.; Kwan, C.; Suvorova, A.; Ang, H.M.; Tadé, M.O.; Wang, S. Catalytic oxidation of organic pollutants on pristine and surface nitrogen-modified carbon nanotubes with sulfate radicals. Appl. Catal. B Environ. 2014, 154, 134-141. [CrossRef]

42. Santos, D.F.M.; Soares, O.S.G.P.; Silva, A.M.T.; Figueiredo, J.L.; Pereira, M.F.R. Catalytic wet oxidation of organic compounds over n-doped carbon nanotubes in batch and continuous operation. Appl. Catal. B Environ. 2016, 199, 361-371. [CrossRef]

43. Liu, Y.; Wang, D.; Sun, B.; Zhu, X. Aqueous 4-nitrophenol decomposition and hydrogen peroxide formation induced by contact glow discharge electrolysis. J. Hazard. Mater. 2010, 181, 1010-1015. [CrossRef]

44. Sun, S.-P.; Lemley, A.T. P-nitrophenol degradation by a heterogeneous fenton-like reaction on nano-magnetite: Process optimization, kinetics, and degradation pathways. J. Mol. Catal. A Chem. 2011, 349, 71-79. [CrossRef]

45. Rodrigues, C.S.D.; Borges, R.A.C.; Lima, V.N.; Madeira, L.M. P-nitrophenol degradation by fenton's oxidation in a bubble column reactor. J. Environ. Manag. 2018, 206, 774-785. [CrossRef]

46. Wang, Y.; Wei, H.; Liu, P.; Yu, Y.; Zhao, Y.; Li, X.; Jiang, W.; Wang, J.; Yang, X.; Sun, C. Effect of structural defects on activated carbon catalysts in catalytic wet peroxide oxidation of m-cresol. Catal. Today 2015, 258, 120-131. [CrossRef]

47. Zazo, J.A.; Casas, J.A.; Mohedano, A.F.; Rodríguez, J.J. Catalytic wet peroxide oxidation of phenol with a fe/active carbon catalyst. Appl. Catal. B Environ. 2006, 65, 261-268. [CrossRef]

48. Ribeiro, R.S.; Fathy, N.A.; Attia, A.A.; Silva, A.M.T.; Faria, J.L.; Gomes, H.T. Activated carbon xerogels for the removal of the anionic azo dyes orange ii and chromotrope $2 \mathrm{r}$ by adsorption and catalytic wet peroxide oxidation. Chem. Eng. J. 2012, 195-196, 112-121. [CrossRef]

49. Gomes, H.T.; Miranda, S.M.; Sampaio, M.J.; Silva, A.M.T.; Faria, J.L. Activated carbons treated with sulphuric acid: Catalysts for catalytic wet peroxide oxidation. Catal. Today 2010, 151, 153-158. [CrossRef]

50. Sousa, J.P.S.; Pereira, M.F.R.; Figueiredo, J.L. Carbon xerogel catalyst for no oxidation. Catalysts 2012, 2, 447. [CrossRef]

51. Sousa, J.P.S.; Pereira, M.F.R.; Figueiredo, J.L. No oxidation over nitrogen doped carbon xerogels. Appl. Catal. B Environ. 2012, 125, 398-408. [CrossRef]

52. Soares, O.S.G.P.; Órfão, J.J.M.; Gallegos-Suarez, E.; Castillejos, E.; Rodriguez-Ramos, I.; Pereira, M.F.R. Nitrate reduction over a pd-cu/mwcnt catalyst: Application to a polluted groundwater. Environ. Technol. 2012, 33, 2353-2358. [CrossRef]

53. Bhatti, Z.I.; Toda, H.; Furukawa, K. P-nitrophenol degradation by activated sludge attached on nonwovens. Water Res. 2002, 36, 1135-1142. [CrossRef] 
54. APHA; AWWA; WEF. Standard Methods for the Examination of Water and Wastewater, 20th ed.; American Public Health Association, American Water Works Association, Water Pollution Control Federation: Washington, DC, USA, 1998.

55. Sellers, R.M. Spectrophotometric determination of hydrogen peroxide using potassium titanium (IV) oxalate. Analyst 1980, 105, 950-954. [CrossRef]

56. Wang, J.; Guo, Y.; Gao, J.; Jin, X.; Wang, Z.; Wang, B.; Li, K.; Li, Y. Detection and comparison of reactive oxygen species (Ros) generated by chlorophyllin metal ( $\mathrm{Fe}, \mathrm{Mg}$ and $\mathrm{Cu}$ ) complexes under ultrasonic and visible-light irradiation. Ultrason. Sonochem. 2011, 18, 1028-1034. [CrossRef]

(C) 2019 by the authors. Licensee MDPI, Basel, Switzerland. This article is an open access article distributed under the terms and conditions of the Creative Commons Attribution (CC BY) license (http://creativecommons.org/licenses/by/4.0/). 